Check for updates

Montreal

Cite this as: $B M J 2021 ; 374: \mathrm{n} 2390$

http://dx.doi.org/10.1136/bmi.n2390

Published: 28 September 2021

\title{
Covid-19: New York's health workers agree to vaccinate as mandate bites
}

\section{Owen Dyer}

A predicted staffing crisis in hospitals around New York state seems to have been largely averted as thousands of healthcare workers, who until now had refused vaccination, agreed to receive last minute shots rather than face potential dismissal.

The state's deadline expired at 1159 pm on Monday 27 September, from which point no unvaccinated person may work in a healthcare facility or nursing home. The vaccination rate last week among New York's roughly 600 ooo healthcare workers was $84 \%$; by Monday it had risen to $92 \%$. In New York City the number of unvaccinated health workers fell over the weekend from more than 8000 to about 5000.

The rush to vaccinate will be seen as a vindication of the approach taken by the state governor, Kathy Hochul, who refused numerous calls to grant extensions or exemptions. Hochul said on Friday that she might mobilise the National Guard to plug gaps or might recruit temporary workers from abroad.

Other state governments have been watching New York to gauge the success of its health worker vaccine mandate, the country's first. Colorado, Maine, Oregon, Rhode Island, and Washington have also announced such mandates, but New York set the earliest deadline.

The state is still fighting eight legal challenges to the mandate. In one case, health workers who claim religious exemption to vaccination were granted a reprieve against the mandate until 12 October by a temporary court injunction.

Reports on the first morning of the New York mandate's application suggest that, for now, unpaid suspension rather than dismissal awaits many of the workers still holding out, as their employers believe that more will accept vaccination in the coming days. But hospitals have already resigned themselves to losing some staff.

The North Carolina based hospital system Novant Health suspended 375 workers last week, giving them five days to be vaccinated. Almost 200 have since done so, said Novant Health, while about 175 have now been fired, the largest mass termination yet of health workers refusing vaccine. Overall, Novant said, more than $99 \%$ of its 35 ooo staff chose vaccination.

\section{Roles affected}

Numerous individual hospitals around the US have imposed their own vaccine mandates. Nurses have higher rates of refusal than doctors and have resigned at higher rates. Temporary medical staffing agencies are charging record fees, with nurses in some cases commanding higher rates than physicians.
Lewis County health system in upstate New York was hit hard by vaccine refusals among clinical staff and had to suspend baby deliveries this weekend after half of the staff in its maternity unit resigned over the mandate. But vaccine refusals are generally more concentrated among people working in administrative, catering, and maintenance roles. Almost all doctors and about $95 \%$ of nurses in New York state are vaccinated.

Another hard hit hospital was Erie County Medical Center in Buffalo, whose chief executive, Tom Quatroche, told the Washington Post that he was surprised to see one employee in 10-about 400 people-still unvaccinated as the deadline passed. "The vaccine mandate was done for all the right reasons and with all the right intentions," he said. "But the reality on the ground is that we're not able to take care of patients appropriately."

Ahead of the deadline the hospital suspended elective inpatient surgeries, paused some transfers to its intensive care unit, and cut the hours at its outpatient clinics, whose workers were "putting on scrubs" to care for inpatients, Quatroche said.

In the final hours over 100 staff came in for last minute vaccinations, and the 276 staff who remained unvaccinated were placed on unpaid leave. They included $20 \%$ of staff at the hospital's affiliated nursing home. The hospital already had over 400 job vacancies and a record number of patients.

Strong Memorial Hospital in Rochester also stopped booking elective procedures as the deadline loomed, but by the time it elapsed its staff vaccination rate had reached $95.5 \%$, up from $92 \%$ last week.

Many of the last minute recipients remained sceptical but did not want to lose their jobs, the hospital's chief operating officer, Kathleen Parrinello, told the New York Times. "Some are still very scared," she said. "So they need hand holding and reassurance." 